\title{
Practice of Teaching Reform of Network Security Technology Course under the Background of Internet+
}

\author{
Ying Zou and Leian Liu
}

\begin{abstract}
Network security technology is an important professional course for computers and related majors. It has the characteristics of wide content, pre-requisite knowledge, fast curriculum knowledge update and strong practical practice. In this paper, the teaching content, teaching methods and assessment methods of the course have been reformed for the problems existing in the teaching of network security technology courses. Practice has shown that reforms have stimulated students' interest in learning and improved their ability to apply knowledge.
\end{abstract}

Index Terms-Network security technology, participatory teaching, competition-driven, applied undergraduate.

\section{INTRODUCTION}

From "Panda Burning Incense" to obtain or destroy user data [1] to the sensational "Eternal Blue" spread ransomware incident [2], from the US Snowden "Prism Gate" event [3] to the largest data leakage in the history of Facebook [4], network security incidents emerge one after another. Information security is suffering more and more serious challenges and people are increasingly aware of its importance. Information security is not only about personal privacy and property security, but also about the security of businesses, society, and the country as a whole. Xi Jinping, general secretary of the Communist Party of China, put forward the important thesis that "there is no national security without network security, no modernization without informationization", "there must be a team of high-quality network security and information talents". The guidelines and lines of the CPC central committee on strengthening network security and informationization work are profoundly expounded.

Network security is a comprehensive interdisciplinary subject involving computer science, network technology, information security technology, communication technology,

Manuscript received October 30, 2018; revised March 3, 2019. This work was financially supported by the quality resource sharing course project-"Computer Network" (Official document by Department of education of Guangdong Province ([2015] no. 133)), the provincial-level characteristic specialty-"Network Engineering" and the provincial teaching team-"Teaching team of basic core course of computer major" (Official document by Department of education of Guangdong Province ([2017]214)), 2018 higher education teaching reform project of Guangdong Province-"Reform and practice of the training mode of network engineering talents based on the cooperation of school-school and school-enterprise", the university-level high-quality resource sharing course project-"Network Security Technology" and "Wireless Sensor Network and RFID Technology", and the Science and Technology Planning Project of Guangdong Province under Grant (2017A070709012).

The authors are with the College of Information Science and Technology of Zhongkai University of Agriculture and Engineering, China (e-mail: blueleaf@126.com, 1la@zhku.edu.cn). computational mathematics, cryptography and information theory. It is an important part of computer and information science, and it is also a new subject developed in the past 20 years [5]. The course content is wide, a lot of preliminary knowledge is needed, and the knowledge is updated quickly. In the teaching process, the teacher often emphasizes the importance of the theory one-sidedly, which leads to the teaching method based on lectures and spoon-feeding. The passive way of receiving knowledge is difficult to stimulate students' interest in learning. After learning, students often seem to have only a hazy notion. When they face practical problems, they can't get started. They can't achieve the purpose of applying what they have learned, which leads to the lack of high-skilled application talents. In order to cultivate the application-oriented talents that the society needs, it is of great significance to carry out teaching reform and innovation for the current undergraduate course of "Network Security Technology" [6]-[9].

As a provincial and local undergraduate college, due to objective reasons, our school has not yet established a special information security major. But based on information security factors such as the Internet era, we offer network security technology courses for the students major in computer science and technology, information management and information systems, network engineering, Internet of things engineering and IT-related majors. Since the course requires a certain amount of computer expertise, it is usually arranged after the third year of the university. The course of network security technology has been offered in our school for many years. This article expounds our working in the course teaching reform based on several aspects such as teaching content, teaching methods and assessment methods. The content of the curriculum reform is shown in Fig. 1.

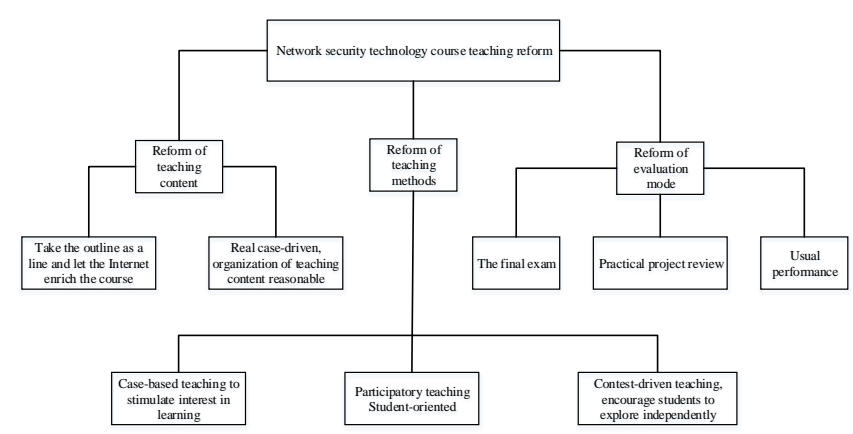

Fig. 1. Schematic diagram of the curriculum reform.

\section{TEACHING CONTENT REFORM}

The course covers the basics of network security, network attack and defense, cryptography, identity authentication technology, firewall technology, virtual private network 
technology and malicious code prevention technology, and so on. The course content is wide and covers a wide range of knowledge. With the rapid development and wide application of information technology, the connotation of network security is also expanding. The teaching content of network security technology courses also needs to be updated in time, but traditional teaching is difficult to do at this point. Knowledge in teaching materials is always outdated [10], [11]. The content of the textbook is mainly based on theory, which weakens the cultivation of students' professional skills Students have mastered the theoretical knowledge but feel that it is useless. They cannot use the theoretical knowledge they have learned to solve practical security problems, and thus lose interest in the network security technology course [12]. How to optimize the content of the course and strengthen the novelty and practicality of the teaching content is an urgent problem to be solved. Our school has reformed from the following two aspects in the teaching process.

\section{A. Take the Outline as a Line and Let the Internet Enrich the Course}

On March 5, 2015, Premier Li Keqiang first proposed the concept of "Internet+" when he made a government work report at the Third Session of the 12th National People's Congress. Integrating the Internet platform with different fields such as finance, commerce, and education can create a new ecology and realizes all-round development and innovation in various fields. The massiveness of Internet teaching resources and the timely and targeted update of teaching content can well solve the problems in network security course, such as wide range of content, more preparatory knowledge, more predecessor courses, and faster knowledge update. We can make full use of Internet resources in teaching to make up for the shortcomings of existing teaching. Due to the rapid development of network security technology, the contents of the textbook are difficult to keep up with. Therefore, in the teaching of specific chapters, we should not stick to the textbook. We must base ourselves on the latest technology and grasp the new trends of the technology. This requires the outline as the main line, allowing the Internet to enrich the curriculum, guiding courses, and innovative courses. Classroom teaching should look for materials from the Internet and achieve open and integrated learning.

For example, in the first class, we will introduce the public numbers and technical forums of some of the more well-known global Internet security new media to students, guide students to pay attention to the teaching resources on the learning network, and help them to understand the most cutting-edge information and technology. It's like that good old saying - "Gives the human by the fish to be inferior gives the human by the fishing".

\section{B. Real Case-Driven and Organization of Teaching Content Reasonable}

Aiming at the technical and practical characteristics of the course, many of cases and simultaneous experiments are added in the classroom teaching, and various offensive and defensive platforms built by enterprises with cooperative relations with the college are used to guide students to conduct simulated practical exercises. During the teaching process, it is as close as possible to the students' interest and the actual needs of students' life and work, so that students can feel useful, effective and rewarding, and achieve good teaching results. For example, when introducing information hiding technology, we first show students the acrostic poetry in "Water Margin". Then use the steganographic tool MP3Stego [13] shows students how to hide txt documents into audio files. The introduction of these two cases greatly enhances students' interest in learning.

Since the course itself is a new subject, the theoretical and practical requirements of the course are relatively high. It is necessary to strengthen the construction of teachers and improve the professional level of teachers themselves. To build a "double-qualified" teaching team with solid theoretical knowledge and strong practical ability is of great significance for the improvement of talent cultivation quality. In order to better carry out the teaching of this course, on the one hand, improve the theoretical level and scientific research ability of teachers, and actively choose the teaching team of this course to enter famous universities in China for visiting studies. In the latest three years, we successively sent teachers to South China University of Technology, Jinan University and Sun Yat-sen University for visiting studies; On the other hand, for the sake of improve the actual network security technical practice ability of the teachers in this course team, we jointly develop the "double-qualified" teacher team training mechanism with the cooperative enterprises. The young teachers of this course team take two vacations every year to work and study in IT enterprises to learn about the latest technologies of network security technology-related industries and apply them to teaching. Fig. 2 shows the industry certification obtained by a teacher of the course teaching team.

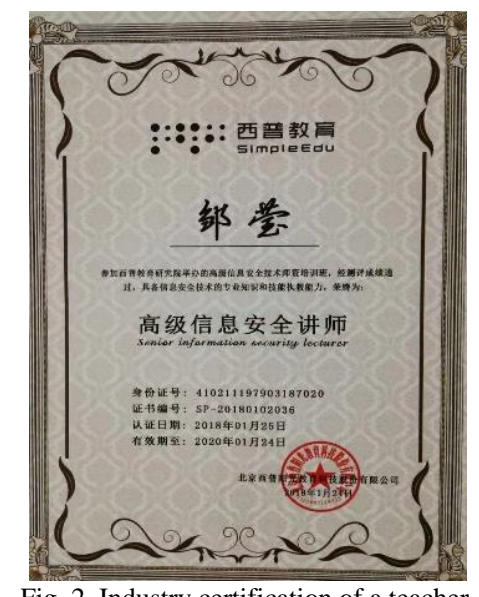

Fig. 2. Industry certification of a teacher.

\section{TEACHING Method REFORM}

For the theoretically strong content such as network security foundation and cryptography, the teaching method is appropriate. But for the content that emphasis on technical and practical such as network attack and defense, firewall technology and other technical and practical emphasis, the teaching method is not appropriate. In accordance with the characteristics of teaching content, we have adopted the following three teaching methods for the characteristics of the teaching content. 


\section{A. Participative Teaching, Student-Oriented}

Participative teaching [14] is an educational model in which teachers and students are placed in the same position in education and teaching. They may exchange ideas and encourage each other in the process of teaching and learning, to mobilize students' active participation and creative learning and development. The network security technology courses are mostly offered in the second semester of junior year or the first semester of senior year. Students have acquired certain basic knowledge and learning ability, which encourages them to participate in the whole process of teaching and is helpful to strengthen the information exchange between teachers and students. So that students can deeply understand and master the knowledge they have learned, which can promote the improvement of their comprehensive ability.

During the teaching process, after explaining the theoretical basis of a certain network technology, the application and practice of the technology are given to the students to participate. For example, SQL injection attacks and defenses, firewall technology applications, IPSec technology applications, the use of mail encryption software PGP, system security scanning technology, and so on, are completed by students in the form of practical projects. Students can work in groups. Before the start of the course teaching, arrange the projects to the students, and let the students freely group, usually three to five, each group can choose one of the projects given by the teacher. Make sure each student belongs to one group. Only if team members work hand in glove to better complete the task of data discovery and collection, program or program design, implementation, analysis and summary, and production of PPT, etc. When reporting the results, the students can freely ask questions, answer by the group members, and finally score according to the integrity of the practice process, the difficulty and complexity of the practice content, the classroom presentation and answer questions. The teacher and group evaluation combined to obtain the group's practice score.

This learning mode fully mobilizes students' enthusiasm for learning and the desire to explore knowledge. It also cultivates students' self-learning ability, practical ability and teamwork spirit. Practice shows that this teaching method is obvious for improving the teaching quality of the course. Fig. 3 shows the on-site report of the PGP group students.

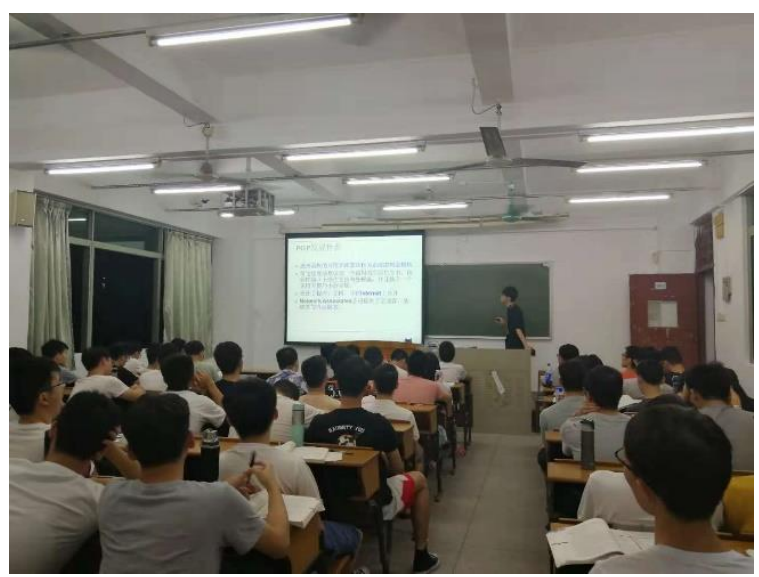

Fig. 3. PGP software group on-site reporting.

\section{B. Case-Based Teaching to Stimulate Interest in Learning}

The case can be security incidents in recent years, especially the security incident having a great influence on society, or the case that students are more interested in. The case also can be a specific network attack and defense, malicious code. Security incidents may help students to understand the need for course learning, from analyzing the impact of these security incidents on information security to what techniques can be used to avoid security incidents, leading to specific teaching content in the class, guiding students through course learning step by step. Specific network attack and defense cases can increase the practicality and fun of the classroom. Breaking the previous classrooms is mostly a "paper talk" situation, which can greatly enhance students' interest in learning.

For example, when talking about the foundation of network security, from the prism door event that students know, analyze the background of the event, the cause of the event, and then analyze the principle that the monitoring plan violates information security, which leads to the concept of network security, risk analysis, and challenges network security facing and other teaching content.

Another example is when talking about Windows system security, began with the "eternal blue" virus, which students very interested in, demonstrate the attack process in class, let students see the whole process and consequences of its invasion, and then analyze how to defense it based on Windows operation system. Then, tell students as a security management, system security reinforce is a very important step. At this time, the students' interest in learning has been stimulated, and they can actively participate in the process of exploring the content of the classroom, which further reflects the subjective status of the students. At the same time, students can gain a wider range of knowledge in the process of inquiry and dispelling, thus enhancing the self-confidence of learning.

\section{Contest-Driven Teaching, Encourage Students to Explore Independently}

In order to encourage students to think independently and cultivate innovative thinking, for the content which have both theoretical and practical, such as web security, cryptography, information steganography, penetration testing, etc., take the Jeopardy Mode of Capture the Flag (CTF) [15] in the teaching process to stimulates students' curiosity and winning psychology. Using the experimental platform of the cooperative enterprise, the teacher first selects the topic and security technology tools from the experiment. After explaining the theoretical basis of the knowledge points, the students may learn the use of safety technology tools through the case. Then, the students are encouraged to use a variety of technical means to solve the specified problem, according to the score and time of the problem to rank the results. In the classroom, special time is reserved for students to share their knowledge and skills in the process of solving problems and exchange learning experiences.

Teaching practice found that the competition-driven model played a positive role in promoting students' active learning. Students were interested in CTF competition. Many students submitted problem-solving reports late at night, and some 
non-designated topics also became the target of students. The course's study made students have a strong interest in the information security competition. Students formed a team participated in the National Xipu Cup Information Security Triathlon in May this year, and won the second award. Fig. 4 is the student award certificate.

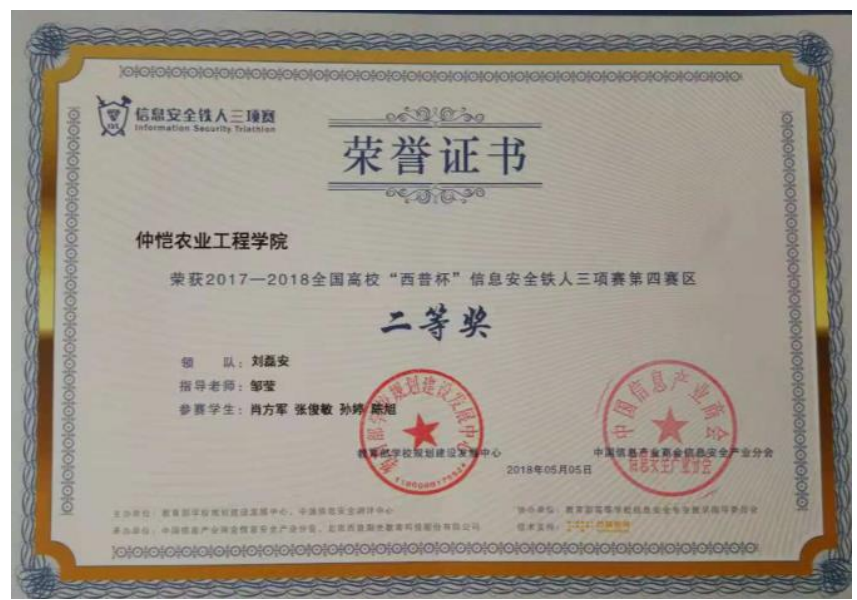

Fig. 4. Student award certificate.

\section{Evaluation Mode REForm}

The reform of the course teaching emphasizes the cultivation of students' practical ability and innovative spirit. Therefore, in the evaluation process, more attention should be paid to the process evaluation, which not only pays attention to the results of student learning, but also pay attention to the active participation of students in learning and the actual situation of the completion of teaching activities [16]. The evaluation of students' learning outcomes consists of three parts: regular final exam scores, practical project scores, and usual performance.

Regular exams are organized by mastering the curriculum objectives and requirements stipulated in the syllabus to examine students' ability to understand knowledge and their ability to think and express. The results of the practical project are evaluated based on the students' division of labor and on-site performance in the practice project. The usual performance consists of attendances, CTF scores and experimental grades. Each achievement proportion is shown in Fig. 5.

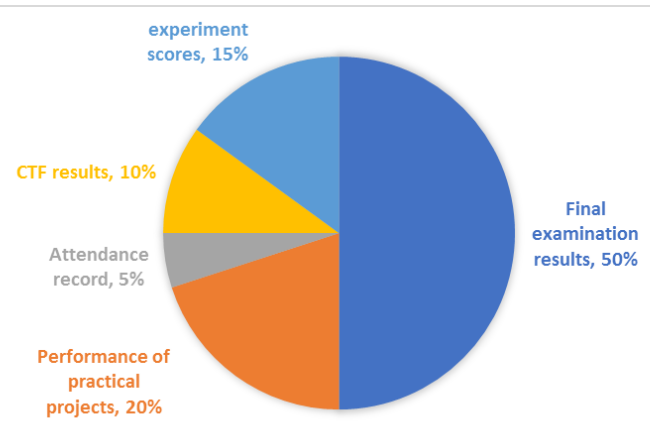

Fig. 5. Proportion of performance evaluation.

\section{CONCLUSION}

In order to ensure the teaching quality of network security technology in colleges and universities, it is imperative to carry out reforms on teaching content and teaching methods. Especially for the application-oriented colleges where the author is located, it is necessary to attach great importance to the cultivation of students' practical ability. This paper has reformed the teaching of the course from three aspects: teaching content, teaching methods and assessment methods, and achieved good teaching results.

The next step will be to continuously adjust and update the teaching content according to the feedback from students and cooperative enterprises, and further improve the setting of practical projects and the arrangement of CTF topics to make them more in line with the needs of talent cultivation.

\section{ACKNOWLEDGMENT}

I would like to take this opportunity to thank my colleague, Leian Liu. He is the associate dean in charge of teaching in our department and the leader of the network technology core course teaching team. In the process of writing this paper, he gave me great help and gave me a lot of guidance in professional development.

\section{REFERENCES}

[1] X. W. Zheng and R. X. Li, "Dissect the panda burning incense," China Education Network, no. 3, pp. 52-53, March 2007.

[2] J. S. Miao, L. J. Yang, and W. P. Yao, "Talk about network security from EternalBlue," Computer Knowledge and Technology, vol. 13, no. 25, pp. 52-54, September 2017

[3] N. Li, "Prism door exposes privacy crisis in the age of big data," Science \& Technology Review, vol. 31, no. 18, p. 9, June 2013.

[4] S. Y. Wei, "Network operators' responsibility for the security management of third-party applications seen from the Facebook data breach," Information Security and Technology, no. 3, pp. 43-46, March 2018.

[5] T. J. Jia, Network Security Technology and Application, 3rd ed. Beijing, China: China Machine Press, 2017, ch. 1, p. 2.

[6] M. Xiao and M. Guo, "Research on the teaching reform of network security courses in applied undergraduate universities," Course Education Research, no. 17, pp. 45-47, April 2017.

[7] X. G. Li and N. Lin, "Teaching practice and innovation of "network security' course," Journal of Shenyang Aerospace University, vol. 34, no. s1, pp. 92-95, March 2017.

[8] J. Y. Li, P. Liu, and Q. He, "Reform and practice of network security training based on CDIO mode," Education Modernization, no. 49, pp. 100-103, December 2017.

[9] L. J. Wei, "Research on the teaching mode of computer network security course," Software Guide, no. 10, pp. 76-77, October 2017.

[10] N. Li, "An analysis of information network security course teaching in colleges and universities," Computer Knowledge and Technology, vol. 13, no. 13, pp. 124-125, May 2017.

[11] L. L. Yan, Y. Chang, and S. B. Zhang, "Network security technology course teaching reform and practice exploration," Computer Education, no. 9, pp. 15-17, September 2016.

[12] H. Zhao and L. X. Wang, "College computer network security course teaching reform and practice," Journal of Lanzhou University of Arts and Science (Natural Science Edition), vol. 29, no. 1, pp. 113-126, January 2015.

[13] C. Jin, R. Wang, and D. Yan, "Steganalysis of MP3Stego with low embedding-rate using Markov feature," Multimedia Tools \& Applications, vol. 76, no. 5, pp. 1-16, May 2017.

[14] Y. M. Cao, "Application skills of participatory teaching in classroom teaching in colleges and universities," University Education, no. 11, pp. 112-114, November 2012.

[15] W. M. Wei, S. Yang, and H. Feng, "Information security classroom teaching combined with CTF competition mode," Computer Education, no. 6, pp. 23-27, June 2017.

[16] D. P. Wang, "Research on assessment methods of information security courses," Software Guide, no. 2, pp. 78-80, February 2018. 


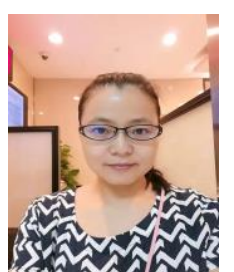

Ying Zou was born in Henan, China in 1979. She is currently a lecturer in Zhongkai University of Agriculture and Engineering, China. She is a member of China Computer Federation. She received the master's degree in computer application technology from Guangxi University. Her research interests include network security technology, IoT technology and machine learning.

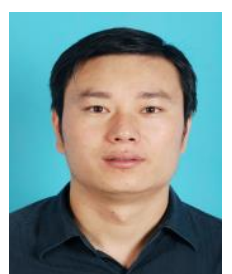

Leian Liu is an associate professor in computer science and technology, Zhongkai University of Agriculture and Engineering, China. He received the Ph.D. in circuits and systems from South China University of Technology. He is a member of Guangdong Institute of Electronics and China Computer Federation. Currently,

he is interested in the research areas such as IoT technology, network security, and embedded technology, etc. security, and embedded technology, etc. 